\title{
表面活性化法を用いた常温ウェハ接合技術
}

\author{
内海 淳 $^{1} \cdot$ 井手健介 $^{1} \cdot$ 一柳優子 ${ }^{2}$ \\ ${ }^{1}$ 三菱重工工作機械株式会社 焉520-3080 滋賀県栗東市六地蔵 130 \\ 2 横浜国立大学大学院工学研究院 函 240-8501 神奈川県横浜市保土ヶ谷区常盤台 79-1
}

（2016年 9 月 15 日受付；2016年 12 月 5 日掲載決定）

\section{Room Temperature Wafer Bonding by Surface Activated Method}

\author{
Jun Utsumi ${ }^{1}$, Kensuke $\operatorname{IdE}^{1}$ and Yuko IchiYANAGI ${ }^{2}$
}

${ }^{1}$ Mitsubishi Heavy Industries Machine Tool Co., LTD., 130 Rokujizo, Ritto, Shiga 520-3080

${ }^{2}$ Yokohama National University, 79-1 Tokiwadai, Hodogaya-ku, Yokohama, Kanagawa 240-8501

(Received September 15, 2016 ; Accepted December 5, 2016)

\begin{abstract}
The bonding of metal electrode and insulator hybrid interfaces is one of key techniques in 3D integration technology. As the surface activated bonding ( $\mathrm{SAB}$ ) is carried out at room temperature, the method is expected to be suitable for hybrid bonding. The metal materials such as $\mathrm{Cu}$ or $\mathrm{Al}$ are easy to directly bond using the $\mathrm{SAB}$ method, but insulator materials such as $\mathrm{SiO}_{2}$ or $\mathrm{SiN}$ are difficult. In this report, we propose a new bonding technique for $\mathrm{SiO}_{2} / \mathrm{SiO}_{2}$ bonding at room temperature using only Si ultra-thin films. We confirmed that the surface energy was about $1 \mathrm{~J} / \mathrm{m}^{2}$, which is almost the same value of $\mathrm{Si} / \mathrm{Si}$ bonding prepared at room temperature by $\mathrm{SAB}$. Moreover, we examined the bonding of $\mathrm{Cu} / \mathrm{Cu}$ by the SAB method, and we confirmed that no micro-voids were observed at the bonding interface.
\end{abstract}

KEYWORDS : surface activated bonding, room temperature bonding, bonding interface, $\mathrm{SiO}_{2}$, hybrid bonding

\section{1.は じめに}

現在, 我々が普段手に取る日用品から車雨・航空機や インフラ機器等様々な産業分野・製品において各種接 合・接着技術が用いられており，それらにおける性能向 上・軽量化・低コスト化などへ大きく寄与している。

接合技術としては, 有機接着材や低融点金属材等を接 合中間層として用いる間接的な接合方法と接合材そのも の同士を貼り合わせる直接的な接合方法とに大別され る。生産性・信頼性等を考慮すると直接接合法における 優位性が高いが，ほとんどの直接接合方法では熱処理が 必要となるため, その適用先には制約がある。表面活性 化接合法（Surface Activated Bonding: SAB）を用いた常 温接合技術 ${ }^{1,2)}$ は, 熱処理を必要としない直接接合法で あり, 既に圧力センサ・加速度センサなどの MEMS (Micro Electro Mechanical Systems) センサや異種材料同 士を貼り合わせた高付加価値基板材料等の量産に適用さ

E-mail : jun_utsumi@mhi.co.jp
れている3)。さらに半導体分野では, 微細化による進展 が難しくなってきている中, 今後とも持続的な発展を続 けていくため, 3 次元積層化による高機能・多機能化が 検討されている。特に, 電極と絶縁層が同一面に混在し たハイブリッド面同士を同時接合する技術が必須となる が, 熱処理が必要な従来技術ではスループット・デバイ スダメージ・位置合わせ等に問題を抱える。そこで，こ れらの問題を解決可能な常温接合技術に対する期待が高 まっており，ハイブリッド接合技術の早急な整備が望ま れている。ここでは, ハイブリッド接合を実現するため に常温接合技術を応用した接合方法を中心として紹介す る。

\section{2. 常温接合技術}

\section{1 接合原理}

現在直接接合方法としては，プラズマ活性化接合法 ${ }^{4)}$ が主流となっている。その原理は, 以下のとおりであ る。プラズマ処理により表面を親水化する。その表面に 吸着した水におけるシラノール基間の水素結合により仮 


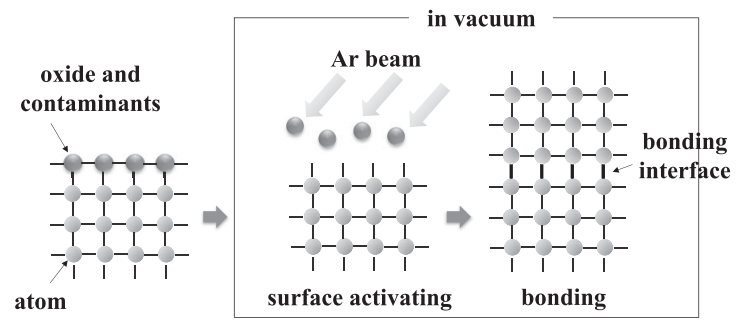

Fig. 1. Schematic illustration of SAB method.

接合する。その後, $300^{\circ} \mathrm{C}$ 程度でアニール处理すること でシラノール基が分解し水素を脱離させることにより強 固な接合を達成する。この接合方法は, SOI（Silicon on Insulator) 基板 Semiconductor）イメージセンサなどの製造に使用され ているが，脱離した水素や過剩水分の残留による接合不 良が発生しやすいこと，また金属材料では接合界面に形 成される酸化層による電気特性への影響などの問題が残 る。

一方，表面活性化法による常温接合技術は，Fig. 1 に 示すように高真空下, Ar イオンビームなどを用いて表 面に存在する自然酸化膜やコンタミネーションを物理的 に除去し，活性化した表面同士を接触させることにより 接合を達成する。そのため, 熱処理を行うことなく母材 同士を直接接合することが可能となる。本接合方法は, 前記プラズマ活性化接合法と同様に恒久的な接合手法で ある。良好な接合特性を得るためには，活性化された状 態を接合まで維持可能な高真空環境および固相間直接接 合では共通となる接合面に打ける原子レベルでの平坦性 確保が重要となる ${ }^{5)}$ 。のように高い前提条件を要する が，熱処理不要の優位性から高周波デバイス用途である $\mathrm{LiTaO}_{3} /$ サファイア接合のように熱膨張率差が大きい異 種材料同士の接合に適している。また，プラズマ活性化 接合法では難しい $\mathrm{Si} / \mathrm{Si}$ 接合においても良好な接合特性 が得られるため, Si プロセスをべースとして構築され る MEMS デバイスへの適用が進んでいる。

\section{2 接合装置}

本研究で使用した常温接合装置（三菱重工社製 MWB-08AX）の概要を Fig. 2 に示す。また，装置の主 な仕様を Table 1 に示す。Fig. 2 に示すように接合試料 は接合面を対向させて上下に配置され，上側試料は静電 チャック（Electrostatic chuck）により固定される。表面 活性化は，上下試料それぞれに対応して配置された高速 原子ビーム（Fast Atom Beam:FAB）源により行う。 FAB は，ソースガスである Ar を中性状態でエネルギー 約 $1 \mathrm{keV}$ 程度のビームを生成する。試料をセッティング

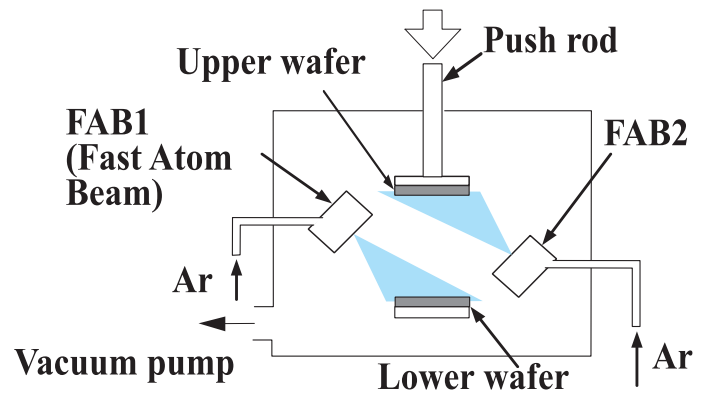

Fig. 2. (color online). Schematic illustration of bonding apparatus.

Table 1. Specifications of MWB-08AX.

\begin{tabular}{ll} 
Set wafers & $10 \mathrm{set}$ \\
Wafer diameter & $200 \mathrm{~mm}$ \\
Operation & Automatic \\
Alignment accuracy & $\pm 2 \mu \mathrm{m}$ \\
Surface activation & FAB \\
Press unit & Max. Press force $100 \mathrm{kN}$ \\
Alignment & By IR transparent Image \\
Degree of vacuum & $<1.0 \times 10^{-5} \mathrm{~Pa}$ \\
\hline
\end{tabular}

し, バックグラウンド真空度が $10^{-6} \mathrm{~Pa}$ 台に達した後, Ar-FAB を照射して上下それぞれの表面を活性化する。 その後, 上側試料を降下させ，下側試料と近接させた状 態で高精度アライメントを行った後, 両者を接触させて 接合する。

\section{3. ハイブリッド接合の実現化に向けた検討}

\section{1 ハイブリッド接合技術}

半導体デバイスの 3 次元積層化には，上下デバイス間 の電気的な接続を確保するために微細な $\mathrm{Si}$ 貫通電極間 を高精度に位置合わせし接合した後，積層を繰り返すた めの薄化・研磨工程が必要となる (Fig. 3 参照)。その ため，金属電極と絶縁材料の混在した面間を同時に接合 するハイブリッド接合では，機械的な強度を絶縁材料間 の接合部で確保する必要がある。これまで，このハイブ リッド接合に対していくつかの検討がされているが ${ }^{6-8)}$, 未だ害用レベルを満足するハイブリッド接合技術は確立 されていない。常温接合法は，熱处理を必要とする従来 の接合技術と比較してハイブリッド接合に対する適用性 に優れていると考えられる。しかしながら，常温接合法 では， $\mathrm{Cu}$ などの金属材料同士では良好な接合特性が得 られるが9 10)， $\mathrm{SiO}_{2}$ や $\mathrm{SiN}$ などに代表される絶縁材料で は表面活性化直後に安定化してしまうため ${ }^{11)}$, 直接接合 することは難しい。そこで本稿では，常温接合法を用い た絶縁材料同士の接合を可能とする新規接合方法に関す 


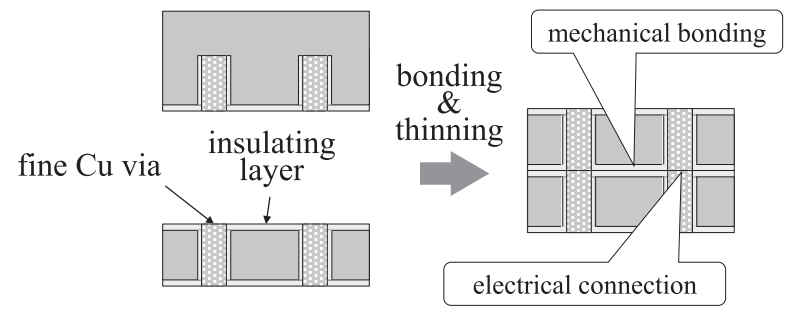

Fig. 3. Hybrid bonding technique.

\section{る検討結果を紹介する。}

\section{2 極薄 $\mathrm{Si}$ 層を用いた $\mathrm{SiO}_{2} / \mathrm{SiO}_{2}$ 接合}

これまでアモルファス $\mathrm{Si}$ 膜を用いた常温による $\mathrm{SiO}_{2}$ 間接合が報告されているが ${ }^{22}$, 接合強度を確保するには 金属膜の介助を必要としている。絶縁層間の接合では, 金属材は絶縁特性に影響するため, 可能な限りその量を 抑える必要がある。ここでは, 厚さ $\mathrm{nm}$ オーダの極薄 $\mathrm{Si}$ 層を接合中間層として $\mathrm{SiO}_{2}$ 同士を金属フリーで接合で きるプロセスを検討した。通常の接合プロセスでは, Fig. 2 に示すように上下に配置したウェハ表面を同時に 活性化するが，ここでは次のような接合プロセスによる $\mathrm{SiO}_{2} / \mathrm{SiO}_{2}$ 接合を検討した。上側に $\phi 8$ インチ熱酸化膜 付 $\mathrm{Si}$ ウェハを, 下側にはターゲットとなる $\phi 8$ インチべ ア Si ウェハを配置する。 $\mathrm{Si}$ ウェハ側のみに Ar ビームを 照射する（第 1 照射）ことによりベア $\mathrm{Si}$ ウェハをスパ ッタリングし, 熱酸化膜表面上に Si 膜を成膜する。そ の後, このスパッタ源として使用した Si ウェハを $\phi 8$ イ ンチ熱酸化膜付 $\mathrm{Si}$ ウェハと入れ換える。次に, Si 膜が 成膜された上側ウェハにAr ビームを照射（第 2 照射） し，下側ウェハ表面上に Si 膜を形成した後，両ウェハ を接合した。接合したウェハの IR 透過像を Fig. 4 に示 す。ボイドもなくウェハ全面で均一な接合状態が得られ ているのが確認できている。ここで使用した IR 透過像 観察装置（モリテックス社製 IRise）では， $\square$ 約 $8 \mathrm{~mm}$ 領域の 1 視野像をステップ・アンド・リピートしてウェ 八全体像を取得するため, 図中に見られる四角パターン はその 1 視野内における照明光強度分布の影響による。

第 1 および第 2 照射時間をそれぞれ 10 min および 2.5 min により接合した $\mathrm{SiO}_{2}$ 間接合界面における透過電子 顕微鏡（Transmission Electron Microscope : TEM）による 観察結果を Fig. 5 に示す。Fig. 5 (a) の低倍像からボイ ド等なく良好な接合状態であることがわかる。また, Fig. 5（b）の高倍像からは接合界面には厚さ約 $7 \mathrm{~nm}$ 程 度のアモルファス $\mathrm{Si}$ 層と思われる中間層が確認できた。 接合界面は, 三角印で示すアモルファス Si 層下部に見 られるコントラストが異なる線状部と思われる。この接

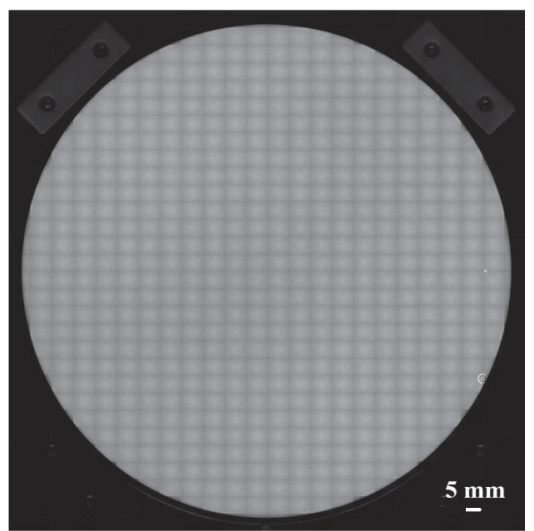

Fig. 4. IR image of the bonded 8 -in. $\mathrm{SiO}_{2} / \mathrm{SiO}_{2}$ wafers using an amorphous Si layer. No voids are visible.

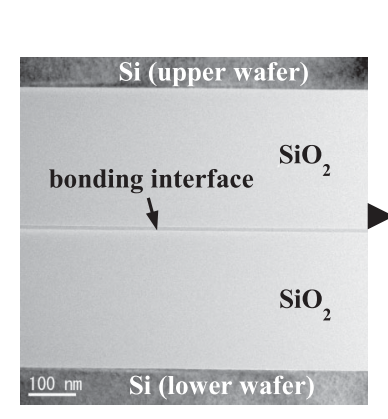

(a)

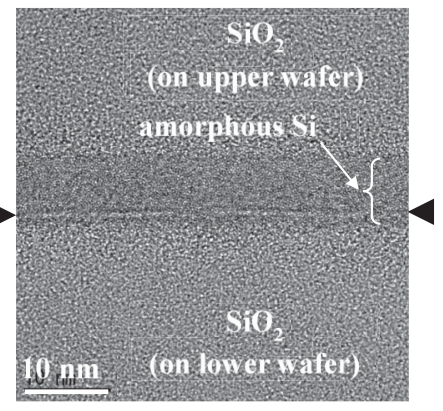

(b)
Fig. 5. TEM cross-sectional images of the bonded $\mathrm{SiO}_{2} /$ $\mathrm{SiO}_{2}$ interface for second irradiation time of $2.5 \mathrm{~min}$ : (a) low magnification and (b) high resolution.

合界面より上層部が第 1 照射により，薄い下層部側が第 2 照射により形成されたアモルファス $\mathrm{Si}$ 層と考えられ る。

さらに, エネルギー分散型 X 線分光法 (Energy Dispersive X-ray Spectroscopy : EDS）を用いて接合界面にお ける元素分析を行った。その結果を Fig. 6 に示す。 $\mathrm{SiO}_{2}$ と中間層の界面，中間層内および接合界面のいずれにお いても $\mathrm{Si}$ と O のみが検出され, 金属種の存在は認めら れなかった。

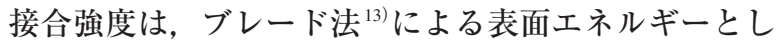
て評価した。第 1 照射時間を $10 \mathrm{~min}$ に固定したときの 第 2 照射時間に対する表面エネルギー測定結果を Fig. 7 に示す。第 2 照射なしでは接合せず，第 2 照射時間 2 $\min$ 以上では表面エネルギー值 $1 \mathrm{~J} / \mathrm{m}^{2}$ 以上が得られた。 この值は，これまで報告されている $\mathrm{SAB}$ 法による $\mathrm{Si} / \mathrm{Si}$ 接合における表面エネルギー值 ${ }^{14)}$ と同程度である。

以上より，常温接合法では直接接合が難しい $\mathrm{SiO}_{2}$ 間 


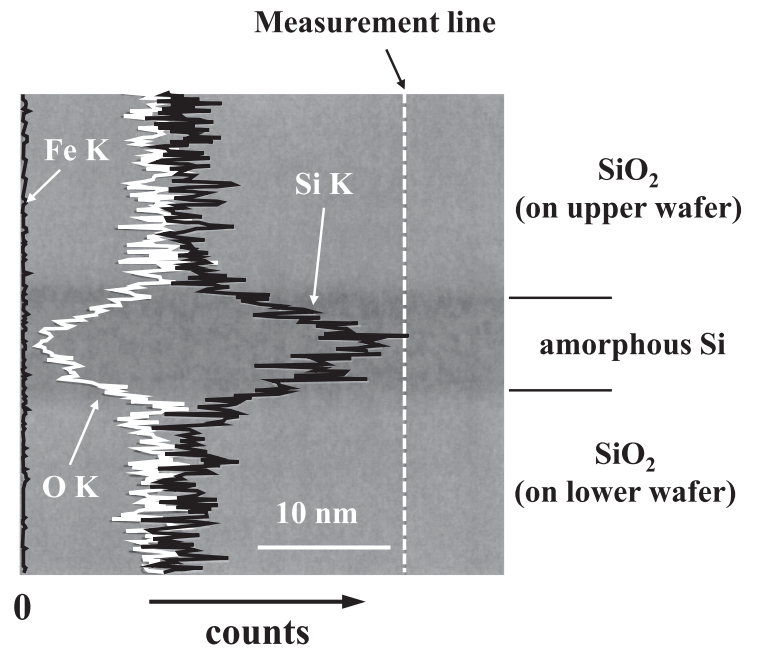

Fig. 6. EDS line analysis along the white dash line on TEM image. The analysis was carried out across the bonding interface.

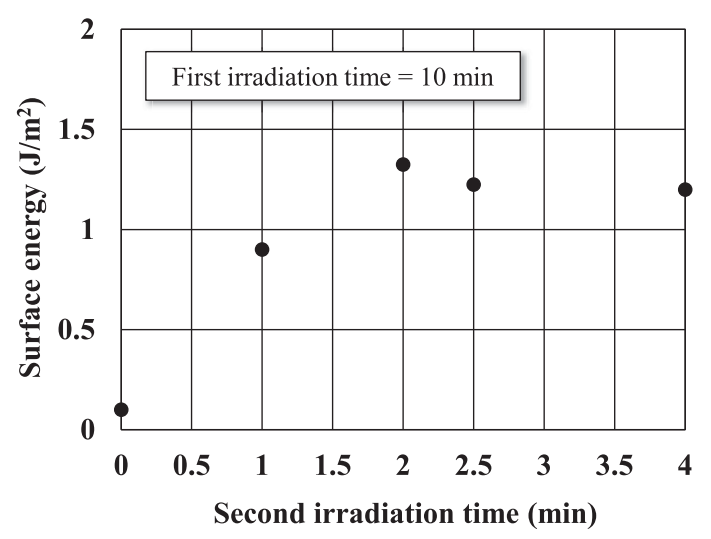

Fig. 7. Relationship between surface energy and irradiation time of the second irradiation. The first irradiation time is 10 $\min$.

接合を極薄 $\mathrm{Si}$ 層を用いて金属フリーな接合を得られる ことが確認できた。

\section{$3.3 \mathrm{Cu} / \mathrm{Cu}$ 接合}

最後に, 電極材となる $\mathrm{Cu} / \mathrm{Cu}$ 接合に関する検討結果 を紹介する。金属材料同士の接合においても良好な接合 特性を得るためには, 十分な表面平坦性が必要となる。 しかしながら, Si のような弾性材料とは異なり, 接合 時の印加荷重による塑性変形効果により接触面積が増大 し，接合強度を向上させることができる ${ }^{15)}$ 。また，通常 金属材の接合に用いられる拡散接合では, その金属材融 点 Tm に対して $0.5 \sim 0.8 \mathrm{Tm}$ 程度の熱処理が必要とされ ている ${ }^{16)}$ 。しかしながら，表面活性化による $\mathrm{Cu} / \mathrm{Cu}$ 接 合において, $100^{\circ} \mathrm{C}$ 程度の低温ポストアニール処理でも 接合強度の向上が確認されている ${ }^{17)}$ 。

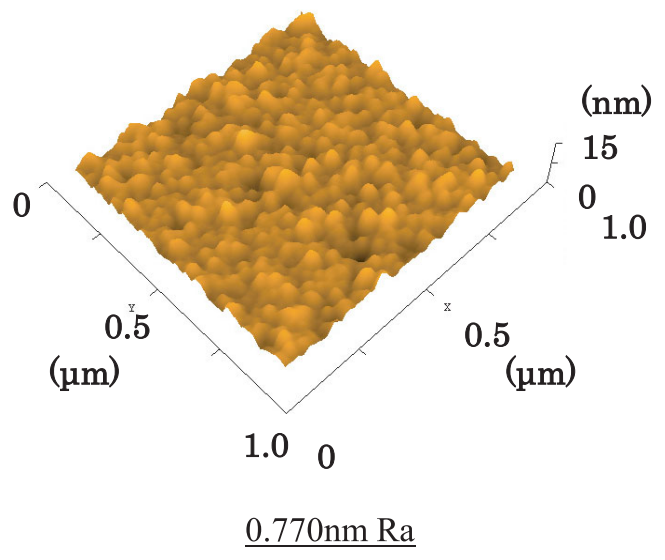

Fig. 8. (color online). AFM images for $\mathrm{Cu}$ surface after CMP treatment. The ra roughness is $0.770 \mathrm{~nm}$. Scanning size is $1 \times 1 \mu \mathrm{m}^{2}$.

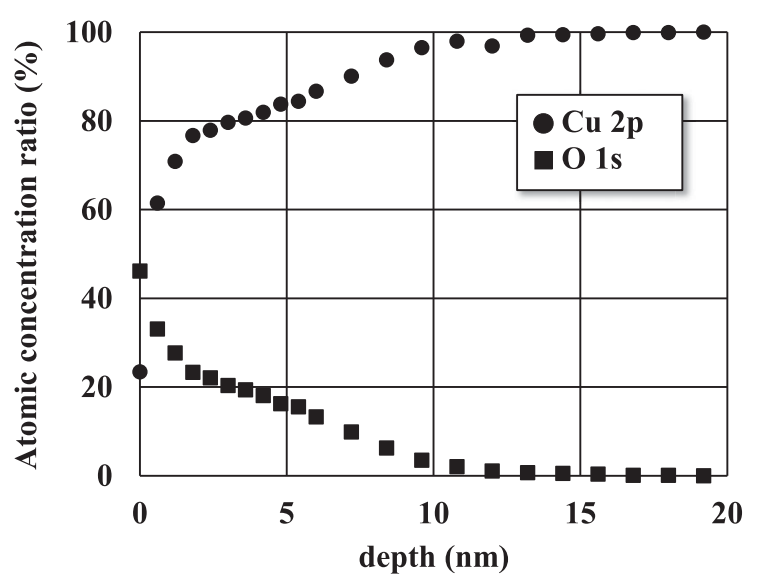

Fig. 9. XPS depth profile of a $\mathrm{Cu}$ deposited film after CMP treatment. ( )are $\mathrm{Cu} 2 \mathrm{p}$ peaks, ( $\square$ ) are O 1s peaks.

以下に，熱酸化膜付 $\mathrm{Si}$ ウェハ表面に成膜した $\mathrm{Cu}$ 膜 を CMP (Chemical mechanical polish) により十分に平坦 化処理し, 常温接合した結果を示す。表面粗さは, 原子 間力顕微鏡 (Atomic Force Microscopy : AFM) を用いて 評価した。Fig. 8 に示すように, 走查エリア $1 \times 1 \mu \mathrm{m}^{2}$ における算術平均粗さ（Ra）值は $0.77 \mathrm{~nm}$ である。ま た, 表面酸化膜の除去量が接合特性および電極間の電気 的接続性に大きく影響するため，その厚さを把握するこ とが重要となる。そこで, $\mathrm{Cu}$ 表面に存在する自然酸化 膜厚を $\mathrm{X}$ 線光電子分光法 (X-ray Photoelectron Spectroscopy : XPS）を用いて深さ分析し測定した。Cu および O それぞれの存在量に関するデプスプロファイルを Fig. 9 に示す。この結果より, 自然酸化膜の厚さは約 $10 \mathrm{~nm}$ 程度であることがわかる。あらかじめ評価した $\mathrm{Cu}$ エッ チング特性に基づいてこの自然酸化膜を十分に除去可能 


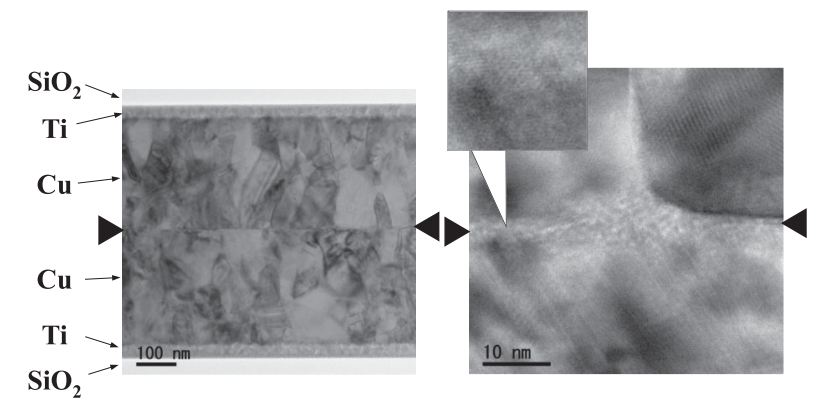

(a)

(b)

Fig. 10. TEM cross-section images of the bonded $\mathrm{Cu} / \mathrm{Cu}$ films interface : (a) low magnification (b) high-resolution.

な条件を決定し，接合処理を行った。接合時の圧接荷重 は約 $40 \mathrm{MPa}$ である。接合した $\mathrm{Cu} / \mathrm{Cu}$ 界面の TEM 観察 像を Fig. 10 に示す。Fig. 10（a）において三角印で示す ように接合界面の境界が認められるが，ボイドもなく均 一に接合しているのがわかる。さらに, Fig. 10（b）に 示す高分解能像において, 三角印で示す接合界面付近で は $\mathrm{Cu}$ 結晶粒とは異なるコントラスト像が確認された。 本 $\mathrm{Cu} / \mathrm{Cu}$ 接合界面部に関しては, EDS による成分分析 から界面上下に打ける $\mathrm{Cu}$ 母材部と組成はほほ同等であ り，また電子エネルギー損失分光法（Electron Energy Loss Spectroscopy : EELS）による状態分析を行った結 果，バルク $\mathrm{Cu}$ と同状態であることを確認している ${ }^{18)}$ 。 それらの結果より，表面活性化により表面酸化膜が十分 に除去されており，また接合界面を横断して格子像が確 認できることから $\mathrm{Cu}$ 同士が直接接合していると考えら れる。

3.2 節で述べた接合中間層として極薄 $\mathrm{Si}$ 膜を用いた 接合方法をハイブリッド接合に適用する場合, 表面活性 化により $\mathrm{Cu}$ 自然酸化膜除去後, Si 膜を成膜する手順と なるため, 活性化後の $\mathrm{Cu}$ 表面も $\mathrm{Si}$ 膜で覆われること になる。そのため, Si 膜による電気的接続性への影響 を把握することが重要となるが，Si 膜厚を極力薄くす ることでその影響を低滅できることが期待される。そこ で, まず $\mathrm{SiO}_{2} / \mathrm{SiO}_{2}$ 接合に扔いて強度確保に必要となる 最低 Si 膜厚を検討し, 膜厚約 $3 \mathrm{~nm}$ 以上で表面エネルギ 一約 $1 \mathrm{~J} / \mathrm{m}^{2}$ が得られることを確認している ${ }^{19)}$ 。今後は, 本接合方法を用いた $\mathrm{Cu} / \mathrm{Cu}$ 電極間接合に扔ける極薄 $\mathrm{Si}$ 膜厚さと電気特性の関係を検討する必要がある。

\section{4. ま と め}

今後半導体デバイスの 3 次元積層化において, 接合技 術はキー技術の一つとなる。特に, 金属電極材と絶縁層 を同時接合するハイブリッド接合技術は必須になると考
えられ，その実現化に向けて常温接合法を利用した取り 組みに関して紹介した。ハイブリッド接合では絶縁層間 接合部で機械的な強度確保が必要となるが, 常温接合法 では $\mathrm{SiO}_{2}$ 系材料の直接接合は難しい。そのため, 極薄 アモルファス $\mathrm{Si}$ 層を用いた接合プロセスを検討し, 常 温接合法による $\mathrm{Si} / \mathrm{Si}$ 接合と同程度の接合強度が得ら れ，本接合プロセスの有效性を示すことができた。今後 は, $\mathrm{SiO}_{2} / \mathrm{SiO}_{2}$ 接合界面における電気的特性評価扔よび 本手法によるハイブリッド面同士の接合評価を進めてい く。

\section{文献}

1) T. Suga, K. Miyazawa and Y. Yamagata: MRS Inter. Meeting on Advanced Materials, Material Research Soc. 8, 257 (1989).

2) T. Suga, Y. Takahashi, H. Takagi, B. Gibbesch and G. Elssner : Acta Metall. Mater. 40, S133 (1992).

3) M. Miura, T. Matsuda, Y. Satoh, M. Ueda, O. Ikata, Y. Ebata and H. Takagi : Proc. IEEE Ultrason. Symp. (2005) p. 573.

4) S.N. Farrens, J.R. Dekker, J.K. Smith and B.E. Roberds : J. Electrochem. Soc. 142, 3949 (1995).

5) H. Takagi, R. Maeda, T.R. Chung, N. Hosoda and T. Suga : Jpn. J. Appl. Phys. 37, 4197 (1998).

6) A. Jourdain, S. Stoukatch, P. De Moor and W. Ruythooren : IEEE Int. Interconnect Technology Conf. (2007) p. 207.

7) J.Q. Lu, J.J. McMahon and R.J. Gutmann : MRS Proc. 1112, 1112-E02-01 (2008).

8) A. Shigetou and T. Suga : J. Electron. Mater. 41, 2274 (2012).

9) T.H. Kim, M.N.R. Howlader, T. Ito and T. Suga : J. Vac. Sci. Technol., A 21, 449 (2003).

10) T.H. Kim, M.M.R. Howlader, T. Itoh and T. Suga : Proc., Int. Symp. on Electronic Materials and Packaging, 3rd IEEE (2001) p. 193.

11）高木秀樹: 機械技術研究所報告 189, 61 (2000).

12) R. Kondo and T. Suga : Proc. of the 61st IEEE Electronic Components and Technology Conf. (2011) p. 2165.

13) W.P. Maszara, G. Goetz, A. Caviglia and J.B. McKitterick : J. Appl. Phys. 64, 4943 (1988).

14) H. Takagi, R. Maeda and T. Suga: J. Micromech. Microeng. 11, 348 (2001).

15) 内海 淳,一柳優子: 電気学会論文誌 E 134, 284 (2014).

16) A. Wang, O. Ohashi and K. Ueno : Mater. Trans. 47, 179 (2006).

17) J. Utsumi and Y. Ichiyanagi : AIP Conference Proceedings 1585, 102 (2014).

18) J. Utsumi and Y. Ichiyanagi : J. Basic and Applied Phys. 3, 150 (2014).

19) J. Utsumi, K. Ide and Y. Ichiyanagi : ECS Trans. 75, 355 (2016). 